\title{
Photo-biohydrogen production potential of Rhodobacter capsulatus-PK from wheat straw
}

Saima Shahzad Mirza ${ }^{1,2^{*}}$, Javed lqbal Qazi ${ }^{1}$, Quanbao Zhao ${ }^{2}$ and Shulin Chen²*

\begin{abstract}
Background: Biotechnological exploitation of lignocellulosic biomass is promising for sustainable and environmentally sound energy provision strategy because of the abundant availability of the renewable resources. Wheat straw (WS) comprising of 75-80\% cellulose and hemicellulose is one of widely available, inexpensive and renewable lignocellulosic biomass types. The cellulosic and hemicellulose substrate can be hydrolyzed into monomeric sugars by chemical and/or biological methods.

Results: This study examined comparative potential of dilute acid and pre-ammonia pretreated and enzymatically hydrolyzed wheat straw (WS) for hydrogen production by purple non sulfur bacterium Rhodobacter capsulatus-PK. Gas production became noticeable after $14 \mathrm{~h}$ of inoculation in WS pretreated with $4 \% \mathrm{H}_{2} \mathrm{SO}_{4}$. The detoxified liquid hydrolyzate (DLH) after overliming attained a production level of $372 \mathrm{~mL}-\mathrm{H}_{2} / \mathrm{L}$ after $16 \mathrm{~h}$ under illumination of $120-150 \mathrm{~W} / \mathrm{m}^{2}$ at $30 \pm 2.0^{\circ} \mathrm{C}$. Whereas the non-detoxified acid pretreated hydrolyzate (NDLH) of WS could produce only upto $254 \mathrm{~mL}-\mathrm{H}_{2} / \mathrm{L}$ after $21 \mathrm{~h}$ post inoculation. Evolution of $\mathrm{H}_{2}$ became observable just after $10 \pm 2.0 \mathrm{~h}$ of inoculation by employing $48 \mathrm{~h}$ age inoculum on the WS pretreated with $30 \%$ ammonia, hydrolyzed with cellulase $80 \mathrm{FPU} / \mathrm{g}$ and $\beta$-glucosidase $220 \mathrm{CbU} / \mathrm{ml}$ at $50^{\circ} \mathrm{C}$. Upto $712 \mathrm{ml} / \mathrm{L}$ of culture was measured with continuous shaking for $24 \mathrm{~h}$. The $47.5 \%$ and $64.2 \%$ higher hydrogen volume than the DLH and NDLH substrates, respectively appeared as a function of significantly higher monomeric sugar contents of the enzymatically hydrolyzed substrate and lesser/zero amounts of toxic derivatives including pH reducing agents.

Conclusion: Photofermentative hydrogen production from lignocellulosic waste is a feasible approach for eco-friendly sustainable supply of bioenergy in a cost-effective way. Results of this study provide new insight for addressing biotechnological exploitation of abundantly available and low-cost cellulosic substrates.
\end{abstract}

Keywords: PNSB, Hydrogen yield, Cellulose, Hydrogen yield and monomeric sugars, Furfural and $\mathrm{H}_{2}$, Acetic acid and $\mathrm{H}_{2}$

\section{Background}

High energy yield without emission of greenhouse gases has rendered hydrogen a clean fuel among all other gaseous fuels [1]. Processes for biological $\mathrm{H}_{2}$ production with low energy input and ambient temperature and pressure requirement are highly desirable for the bioenergy sector [2-4]. Purple non sulfur bacteria (PNSB) are group of microbes which produce $\mathrm{H}_{2}$ photoheterotrophically under a variety of anaerobic environmental conditions in presence of light and at expense of broad range of

\footnotetext{
* Correspondence: azfirin_fatima@yahoo.com; chens@wsu.edu

${ }^{1}$ Microbial Biotechnology Laboratory, Department of Zoology, University of the Punjab, 54590 Lahore, Pakistan

${ }^{2}$ Biological Systems Engineering, Washington State University, Bioprocessing and Bioproduct Engineering Laboratory, Pullman, WA, USA
}

substrates [5]. Production cost of biohydrogen can be reduced by employing suitable low cost lignocellulosic feedstocks [6]. Conversion to monomeric sugars of the cellulosic substrate is the first step in such processes. Acid pretreatment at moderate temperature renders hemicelluloses to hydrolyzate of dissolved sugars with acetic acid $[7,8]$.

Enzymatic hydrolysis of the cellulose is typically environmentally friendly and yields no process inhibitory byproduct, but the process is not economically feasible as high enzyme loading is required in order to obtain reasonable yield $[9,10]$. Pretreatment which alters structure and compositions of lignocellulosic feedstock and makes it more feasible for enzymatic hydrolysis becomes essential in the cellulosic sugar utilization. Removal of 
lignin and uronic acid substitutes on hemicelluloses, reduction of crystallinity and increase of porosity of the plant cell wall in the pretreatment process can significantly improve accessibility of enzyme to hemicelluloses and cellulose [11]. Lignin acts as a glue to hold cellulose and hemicelluloses together. Among different pretreatment processes, ammonia pretreatment has been proven effective in enhancing efficiency of enzymatic saccharification of lignocellulosic substrates [12,13].

In this study, $\mathrm{H}_{2}$ production by enzymatic hydrolysis of ammonia pretreated (delignified) WS was optimized by applying surface response methodology (RSM). The RSM technique is extensively employed for investigation of optimized physiochemical parameters as well as different factors of fermentation media of variety of microbes [14]. Different parameters affecting hydrogen production yield from WS, including inocula age, nitrogen content and amount of substrate were examined. Nitrogenase mediated hydrogen production in purple non sulfur bacteria has also been reported as strongly affected by carbon to nitrogen ratio. Lower carbon to nitrogen ratio slowed down the fermentation process and vice versa. However, presence of excessive fixed nitrogen above critical level in medium repressed nitrogenase activity [15].Further, it was observed that fixed nitrogen is necessary for actively growing cells, especially for $\mathrm{H}_{2}$ production at the expense of nitrogenase. This fixed nitrogen must be provided in the form of some favorable nitrogen contents, because many of them have repressive effect on nitrogenase [16]. This study was mainly aimed at developing a systematic tool for predicting hydrogen production from dilute acid treated and enzymatically hydrolyzed wheat straw (WS) in combination with yeast extract. The results add value to the application of WS for the production of clean fuel.

\section{Results and discussion}

In the present study wheat straw was pretreated with dilute $\mathrm{H}_{2} \mathrm{SO}_{4}$ and ammonia prior to enzymatic hydrolysis in separate set of experiments, according to protocols described by different authors in order to obtain more sugar contents available for $\mathrm{H}_{2}$ production $[13,17,18]$. Chemical and elemental compositions of untreated WS are shown in Tables 1 and 2, respectively. It can be seen from Table 2 that the WS contained mainly glucan $37.23 \%$ and xylan $21.9 \%$.

Micromolecular sugars are relatively easy to be assimilated into the hydrogen-producing bacterial cells [19]. Therefore in order to better exploit WS for hydrogen production, effectiveness of pretreatment methods of the substrate was compared.

\section{Effect of ammonia pretreatment on WS}

WS was analyzed after ammonia pretreatment followed by enzyme hydrolysis for sugars and lignin contents (Tables 2
Table 1 Elemental composition of Wheat Straw (WS) on dry solid basis

\begin{tabular}{llll}
\hline Element & Content $(\boldsymbol{\mu g} / \mathbf{g})$ & Element & Content $(\boldsymbol{\mu g} \mathbf{g})$ \\
\hline $\mathrm{Ca}$ & $2300 \pm 0.54$ & $\mathrm{~K}$ & $12000 \pm 0.50$ \\
$\mathrm{Mg}$ & $600 \pm 0.27$ & $\mathrm{Na}$ & $800 \pm 0.30$ \\
$\mathrm{P}$ & $470 \pm 0.25$ & $\mathrm{~S}$ & $860 \pm 0.25$ \\
$\mathrm{As}$ & $<16$ & $\mathrm{Ba}$ & $25.0 \pm 0.03$ \\
$\mathrm{Cd}$ & $<0.4$ & $\mathrm{Co}$ & $<0.12$ \\
$\mathrm{Cr}$ & $<2$ & $\mathrm{Cu}$ & $1.9 \pm 0.01$ \\
$\mathrm{Fe}$ & $71 \pm 0.30$ & $\mathrm{Mn}$ & $26 \pm 0.30$ \\
$\mathrm{Mo}$ & $<2$ & $\mathrm{Ni}$ & $<2$ \\
$\mathrm{~Pb}$ & $<4$ & $\mathrm{~V}$ & $<0.4$ \\
$\mathrm{Zn}$ & $3.3 \pm 0.1$ & & \\
\hline
\end{tabular}

C\% (on dry basis) $=48 \pm 0.39$;

$\mathrm{N} \%$ (on dry basis) $=0.34 \pm 0.01$;

Values are means of three replicates \pm S.E.M.

and 3). The results showed $20 \%$ removal of lignin following ammonia pretreatment (Table 2). The delignification is in close agreement with the results of Han et al. [6]. Ammonia effectively removes from WS lignin that otherwise hinders the enzymatic access to cellulose $[20,21]$. Han et al. [6] reported WS pretreatment with $15 \%$ (v/v) ammonia before employing cellulase and $\beta$-glucosidase for enzymatic hydrolysis of WS with reduced lignin for ethanol production.

\section{Effect of dilute $\mathrm{H}_{2} \mathrm{SO}_{4}$ pretreatment on WS}

Highest $\mathrm{H}_{2}$ production was observed in $4 \%$ dilute $\mathrm{H}_{2} \mathrm{SO}_{4}$ acid treated WS hydrolysate. Chemical composition of the $4 \%$ acid treated DLH and NDLH is shown in Table 3. In the present study DLH and NDLH portions of the acid treated WS contained xylose and glucose upto 2.01, 2.77 and 9.05 and $11.03 \mathrm{~g} / \mathrm{L}$, respectively in addition to arabinose and galactose. While among the inhibitors acetic acid was prominent. It has been reported by $\mathrm{Yu}$ et al. [13] that dilute acid pretreatment yielded $81.6 \%$ of the monomeric sugars following most of hemicelluloses' dissolution in the hydrolysate. Acetic acid is formed via de-acetylation of hemicelluloses [13]. Coupling of the

$\begin{aligned} & \text { Table } 2 \text { Chemical composition of wheat straw on dry } \\
& \text { solid basis }\end{aligned}$
\begin{tabular}{ccc}
\hline Composition & Dry solid (\%, w/w) & Ammonia pretreatment \\
\hline Glucan & $37.23 \pm 0.24$ & $37.23 \pm 0.24$ \\
Xylan & $21.9 \pm 0.12$ & $21.9 \pm 0.12$ \\
Arabinan & $3.43 \pm 0.98$ & $3.43 \pm 0.98$ \\
Galactan & $1.60 \pm 0.07$ & $1.60 \pm 0.07$ \\
Lignin $^{\text {a }}$ & $12.0 \pm 0.30$ & $9.6 \pm 0.05$ \\
Extractive $^{2}$ & $11.1 \pm 0.20$ & $11.1 \pm 0.20$ \\
\hline
\end{tabular}

${ }^{a}$ Lignin (\%) = acid soluble (\%) + acid insoluble (\%).

Values are means of three replicates \pm S.E.M. 
Table 3 Monosaccharides' concentrations ( $g / L$ ) in fermentation broth (unexhausted and exhausted) of wheat straw (WS)

\begin{tabular}{|c|c|c|c|c|c|c|c|c|c|c|c|c|}
\hline \multirow[t]{3}{*}{ Monosaccharide } & \multicolumn{6}{|c|}{ Unexhausted Broth } & \multicolumn{6}{|c|}{ Exhausted Broth } \\
\hline & \multicolumn{2}{|c|}{ Acid pretreatment $(4 \%)$} & \multicolumn{4}{|c|}{ Enzymatic hydrolysis (Substrates loading in grams) } & \multicolumn{2}{|c|}{ Acid pretreatment $(4 \%)$} & \multicolumn{4}{|c|}{ Enzymatic hydrolysis (Substrates loading in grams) } \\
\hline & DLH & NDLH & 1.0 & 1.5 & 2.0 & 2.5 & DLH & NDLH & 1.0 & 1.5 & 2.0 & 2.5 \\
\hline Glucose & $2.01^{c} \pm 0.00$ & $2.77^{\mathrm{C}} \pm 0.04$ & $54.10^{\mathrm{b}} \pm 1.0$ & $55.03^{\mathrm{a}, \mathrm{b}} \pm 0.43$ & $56.10^{\mathrm{a}} \pm 0.32$ & $57.10^{\mathrm{a}} \pm 0.41$ & $0.03^{c} \pm 0.01$ & $0.04^{c} \pm 0.02$ & $4.54^{\mathrm{b}} \pm 0.10$ & $5.23^{\mathrm{a}, \mathrm{b}} \pm 0.20$ & $6.45^{a} \pm 0.23$ & $7.05^{\mathrm{a}} \pm 0.45$ \\
\hline Xylose & $9.05^{d} \pm 0.16$ & $11.03^{\mathrm{c}} \pm 0.32$ & $17.81^{b, d} \pm 0.3$ & $18.01^{\mathrm{a}} \pm 1.01$ & $21.10^{\mathrm{a}} \pm 0.20$ & $22.10^{\mathrm{a}} \pm 0.30$ & $0.71^{c} \pm 0.30$ & $1.31^{c} \pm 0.03$ & $2.63^{b} \pm 0.10$ & $3.10^{\mathrm{b}} \pm 0.02$ & $3.38^{b} \pm 0.30$ & $5.10^{\mathrm{a}} \pm 0.01$ \\
\hline Arabinose & $4.23^{b, c} \pm 0.18$ & $6.25^{a} \pm 0.23$ & $1.30 \pm 0.10$ & $2.34^{c} \pm 1.0$ & $4.20^{b, c} \pm 0.10$ & $5.10^{b} \pm 0.10$ & - & $0.78^{a} \pm 0.28$ & - & - & $1.11^{a} \pm 0.05$ & $1.12^{\mathrm{a}} \pm 0.04$ \\
\hline Galactose & $5.40^{b} \pm 0.047$ & $6.23^{a} \pm 0.23$ & - & - & $2.20^{\mathrm{a} . \mathrm{c}} \pm 0.04$ & $2.34^{c} \pm 0.11$ & - & - & - & - & $1.10^{\mathrm{a}} \pm 0.02$ & $1.11^{\mathrm{a}} \pm 0.02$ \\
\hline Lignin & - & - & - & - & - & - & - & - & - & - & - & - \\
\hline HMF & $0.26 \pm 0.02$ & $0.59 \pm 0.02$ & - & - & - & - & - & - & - & - & - & - \\
\hline Furfural & 0.00 & $0.03 \pm 0.01$ & - & - & - & - & - & - & - & - & - & - \\
\hline Acetic acid & $2.34 \pm 0.034$ & $0.21 \pm 0.12$ & - & - & - & - & - & - & - & - & - & - \\
\hline
\end{tabular}

Values are means of three replicates \pm S.E.M. 
temperature upto $50^{\circ} \mathrm{C}$ with alkaline $\mathrm{pH}$ (upto 10) was intended for occurrence of overliming process. Detoxification of acid treated WS hydrolysate by process of overliming completely removed furfural, while monosaccharides and acetic acid retained in DLH (Table 3). HMF on the other hand was present in low concentration. The process of overliming resulted in degradation of $27.4 \%$ glucose, $18.05 \%$ xylose, $35.52 \%$ arabinose and $13.32 \%$ galactose. These results are in close agreement with the findings of Mohagheghi et al. [22] who reported 7-34\% loss of xylose.

It was observed in the present study that higher concentrations of $\mathrm{H}_{2} \mathrm{SO}_{4}$ caused increases in the yield of monomeric sugars. Excess acid also increased production of furfural, a consequence of xylose degradation. Pattra et al. [23] reported similar results for concentrated acid treated hydrolysate of sugarcane bagasse. Aguilar et al. [24] while studying the kinetics of acid hydrolysis of sugarcane bagasse also reported higher furfural levels. Adverse effects of furfural on enzymes and inhibition of protein and RNA synthesis damage microorganisms, the agents of fermentations. Acetic acid, furfural and hydroxymethyl furfural are microbial toxicants and thus decrease yield of fermentation products [25-27].

\section{Effect of enzymatic hydrolysis}

Table 3 shows conversion yield of ammonia pretreated wheat straw cellulose into different fermentable sugars. Application of $80 \mathrm{FPU} / \mathrm{g}$ of cellulase and $220 \mathrm{CbU} / \mathrm{ml}$ of $\beta$-glucosidase could yield upto $57.10 \pm 0.41$ and 22.10 $\pm 0.30 \mathrm{~g} / \mathrm{L}$ hexose and pentose for $2.5 \mathrm{~g}$ of wheat straw loading/100 $\mathrm{ml}$ in $50 \mathrm{mM}$ acetate buffer, respectively. The enzymatic hydrolysis of wheat straw thus resulted in higher yield than the dilute acid pretreatment of glucose and xylose (Table 3). Conversion ratio of cellulose to sugars has been reported responsive to enzyme dose with slight difference in digestibility. Pretreated WS has been demonstrated to be hydrolyzed efficiently even with low enzyme dosage $[6,28,29]$.

\section{Hydrogen production experiments}

Maximum hydrogen production was observed in $4 \%$ sulfuric acid pretreated DLH of wheat straw. Although a portion of the sugars lost during overliming process but this treatment resulted in low level of inhibitors.
Consequently, more hydrogen production was recorded when the DLH was employed. Comparatively low $\mathrm{H}_{2}$ from NDLH of dilute acid pretreated wheat straw is attributable to higher amounts of the inhibitors. Anam et al. [30] also reported highest reducing sugar contents obtained by $4 \%(\mathrm{v} / \mathrm{w})$ acid concentration while treating sugarcane bagasse. The author reported glucose and yeast extract as carbon and nitrogen sources, respectively important for growth and maintenance of cells in addition to hydrogen production. Complex fermentation media incorporating starting material of natural origins might be of value for certain fermentation applications. In this study upto $372 \mathrm{ml} / \mathrm{L}$ of $\mathrm{H}_{2}$ volume after $16 \mathrm{hrs}$ was recorded when the acid pretreated DLH of WS was employed. However, in case of Biebl and Pfennig medium (control-MII) where sodium succinate serves as carbon source and yeast extract as nitrogen source for the photofermentation at $30^{\circ} \mathrm{C}, \mathrm{H}_{2}$ production was recorded upto $119 \mathrm{ml} / \mathrm{L}$.

The results are consistent with the reports indicating that alkaline pretreatment of lignocellulosic biomass followed by enzymatic hydrolysis would ultimately lead to improved yield of biohydrogen because of easier access of enzyme into lignocellulosic biomass due to delignification [31-33].

Regarding importance of nitrogen source, Hakobyan et al. [34] reported employment of yeast extract as efficient nitrogen source for biohydrogen production. L-glutamte has been mentioned as most preferred nitrogen source by most of hydrogen producing PNS bacteria [35,36]. For industrial applications, however, other supplements should be investigated, in order to reduce the operational cost and to improve the product yield.

Optimization of parameters like temperature, initial substrate concentration and inoculum age by employing Central Composite Design (CCD) experiments using response surface methodology (RSM) was proved to be an optimum tool. Inoculum age, nitrogen deficit conditions and substrate concentration have been considered as critical parameters for $\mathrm{H}_{2}$ production [37,38]. Details of model obtained from the present study with measured response values in terms of hydrogen production as a function of each corresponding statistical treatment combinations of test variables are summarized in Tables 4, $5 \& 6$. The following regression equation of application of RSM resulted in an empirical relationship:

Table 4 Coded values of the variables for the central composite design

\begin{tabular}{lccccc}
\hline \multicolumn{5}{c}{ Actual values of coded levels } \\
\hline Variables & Coded symbol & -1 & 0 & 1 & -1.6818 \\
-Inoculum age $(\mathrm{h})$ & $\mathrm{X}_{1}$ & 24 & 48 & 72 & 8.00 \\
Nitrogen content $(\mathrm{mg})$ & $\mathrm{X}_{2}$ & 200 & 300 & 400 & 1.6818 \\
Substrate $(\mathrm{g})$ & $\mathrm{X}_{3}$ & 1.5 & 2.0 & 2.5 & 88 \\
\hline
\end{tabular}


Table 5 Central composite design (CCD) matrix of three independent variables for $\mathrm{H}_{2}$ production in actual values with experimental results of WS by employing Rhodobacter capsulatus-PK (SS-8) in the presence of tungsten lamp with light intensity of $120-150 \mathrm{~W} / \mathrm{m}^{2}$

\begin{tabular}{|c|c|c|c|c|c|}
\hline \multirow[t]{2}{*}{ Run No } & \multicolumn{3}{|c|}{ Variables } & \multirow{2}{*}{$\begin{array}{c}\text { Response } \\
\text { Y hydrogen production }(\mathrm{ml})\end{array}$} & \multirow{2}{*}{$\begin{array}{c}\text { Yield } \\
\text { Mole of } \mathrm{H}_{2} / \text { mole of substrat }\end{array}$} \\
\hline & $X_{1}$ & $x_{2}$ & $x_{3}$ & & \\
\hline 1 & -1.000 & -1.000 & -1.000 & 528 & 0.98 \\
\hline 2 & -1.682 & 0.000 & 0.000 & 587 & 1.09 \\
\hline 3 & 1.000 & -1.000 & -1.000 & 597 & 1.11 \\
\hline 4 & 0.000 & 0.000 & 0.000 & 709 & 1.32 \\
\hline 5 & 1.682 & 0.000 & 0.000 & 603 & 1.12 \\
\hline 6 & 0.000 & 0.000 & 0.000 & 709 & 1.32 \\
\hline 7 & 0.000 & 0.000 & 0.000 & 712 & 1.32 \\
\hline 8 & 0.000 & 0.000 & 0.000 & 711 & 1.32 \\
\hline 9 & 1.000 & -1.000 & 1.000 & 561 & 1.04 \\
\hline 10 & 0.000 & 1.682 & 0.000 & 598 & 1.11 \\
\hline 11 & 0.000 & 0.000 & 1.682 & 551 & 1.02 \\
\hline 12 & 0.000 & 0.000 & -1.682 & 559 & 1.04 \\
\hline 13 & 0.000 & 0.000 & 0.000 & 709 & 1.32 \\
\hline 14 & 0.000 & -1.682 & 0.000 & 554 & 1.03 \\
\hline 15 & 0.000 & 0.000 & 0.000 & 709 & 1.32 \\
\hline 16 & 1.000 & 1.000 & 1.000 & 542 & 1.01 \\
\hline 17 & -1.000 & 1.000 & -1.000 & 568 & 1.06 \\
\hline 18 & -1.000 & 1.000 & 1.000 & 572 & 1.06 \\
\hline 19 & 1.000 & 1.000 & -1.000 & 540 & 1.00 \\
\hline 20 & -1.000 & -1.000 & 1.000 & 527 & 0.98 \\
\hline
\end{tabular}

Accordingly:

$$
\begin{aligned}
Y= & \beta_{0}+\beta_{1} X_{1}+\beta_{2} X_{2}+\beta_{3} X_{3}+\beta_{11} X_{1}^{2}+\beta_{22} X_{2}^{2} \\
& +\beta_{33} X_{3}^{2}+\beta_{12} X_{1} X_{2}+\beta_{13} X_{1} X_{3}+\beta_{23} X_{2} X_{3}
\end{aligned}
$$

Here $Y$ represents predicted response, $\beta_{0}$ the constant coefficient, $\beta_{1}, \beta_{2}$, and $\beta_{3}$ the linear coefficients, $\beta_{11}, \beta_{22}$ and $\beta_{33}$ the quadratic coefficients, $\beta_{12}, \beta_{13}$, and $\beta_{23}$ the cross products coefficients and $X_{1}, X_{2}$ and $X_{3}$ were input variables (inoculum age, nitrogen content and substrate loading). From Eq. (1), it can be concluded that in total 20 runs are required for optimized response (Table 5).

Table 6 Analysis of Variance (ANOVA) for the quadratic model

\begin{tabular}{llllll}
\hline Source & SS & DF & MS & $\boldsymbol{F}$ value & Probability $(\boldsymbol{P})>\boldsymbol{F}$ \\
\hline model & 97366.4 & 9 & 10818.4 & 93.93 & $<0.0001$ \\
Residual (error) & 1151.80 & 10 & 115.18 & & \\
Lack of fit & 1142.97 & 5 & 228.59 & 129.39 & \\
Pure error & 8.83 & 5 & 1.77 & & \\
Total & 98518.2 & 19 & & & \\
\hline
\end{tabular}

Coefficient of determination $\left(R^{2}\right)=0.98$; adjusted $R^{2}=0.97$; coefficient of variation $(C V)=1.77 \%$; $S$, sum of squares; $D F$, degree of freedom; MS, mean square.
Analysis of variance (ANOVA) was applied for diagnostic checking of appropriateness of proposed model (Table 6). Coefficient of determination $R^{2}$ and adjusted $R^{2}$ express accuracy and general quality of fitting of the above polynomial model. Three dimensional (3D) surface plots of the fitted polynomial equation illustrate individual and interactive effect of factors on the response within the range of central composite design. The optimum region was also identified based on the main parameters in the overlay plot [39].

$$
\begin{aligned}
Y= & 710.25+5.27 X_{1} \\
& +6.08 X_{2}-3.26 X_{3}-20.12 X_{1}^{2}-4.62 X_{2}^{2} \\
& +5.38 X_{3}^{2}-43.30 X_{1} X_{2}-50.02 X_{1} X_{3}-57.44 X_{2} X_{3}
\end{aligned}
$$

$F$ test verified significance of this model with $F$ value 93.93 and probability $(\mathrm{P})>\mathrm{F}(0.0001)$. As coefficient of variation is indicative of degree of precision of all the compared treatments, therefore low CV (1.77\%) approved the reliability of the model of the present study. However, $\mathrm{R}^{2}=0.98$ also added to the accuracy and consistency of the model as the model predicted and observed values agreed well. Tables 6 \& 7 explains F test values with 
Table 7 Significance of the coefficients of regression

\begin{tabular}{lllll}
\hline $\begin{array}{l}\text { Model } \\
\text { term }\end{array}$ & $\begin{array}{l}\text { Parameter } \\
\text { estimate }\end{array}$ & $\begin{array}{l}\text { Standard } \\
\text { error }\end{array}$ & $\boldsymbol{F}$ value & $\boldsymbol{p}$ value \\
\hline $\mathrm{b}_{0}$ & 710.25 & 4.38 & 3.29 & 0.0999 \\
$\mathrm{~b}_{1}$ & 5.27 & 2.90 & 4.38 & 0.0628 \\
$\mathrm{~b}_{2}$ & 6.08 & 2.90 & 1.26 & 0.2885 \\
$\mathrm{~b}_{3}$ & -3.26 & 2.90 & 28.13 & $0.0003^{\mathrm{a}}$ \\
$\mathrm{b}_{11}$ & -20.12 & 3.79 & 1.49 & 0.2509 \\
$\mathrm{~b}_{22}$ & -4.62 & 3.79 & 2.01 & 0.1870 \\
$\mathrm{~b}_{33}$ & 5.38 & 3.79 & 234.59 & $<0.0001^{a}$ \\
$\mathrm{~b}_{1} \mathrm{~b}_{2}$ & -43.30 & 2.83 & 313.03 & $<0.0001^{a}$ \\
$\mathrm{~b}_{1} \mathrm{~b}_{3}$ & -50.02 & 2.83 & 412.85 & $<0.0001^{a}$ \\
$\mathrm{~b}_{2} \mathrm{~b}_{3}$ & -57.44 & 2.83 &
\end{tabular}

${ }^{a} p$ value less than 0.05 indicate significant model terms.

reference to respective $\mathrm{P}$ values for the estimated parameters. Small P values further approved the significance of the model. Straight line of normal probability showed satisfactory normality assumptions. These parameters appear good indicative of prediction for maximum response within described range of variations of the quadratic model.

\section{Effect of variables on the hydrogen production}

Figure 1A shows the effect of inoculum age and nitrogen content on hydrogen production when substrate loading was at their central point. The yield of $\mathrm{H}_{2}$ production was low with short inoculum age. Significant improvement in $\mathrm{H}_{2}$ production was observed with increases in inoculum age upto $48 \mathrm{~h}$, thereafter the yield decreased with further increments of inoculum age. Basak and Das [40] also reported maximum $\mathrm{H}_{2}$ production with $48 \mathrm{~h}$ inoculum age. Significant improvement in $\mathrm{H}_{2}$ production was also observed initially with increase in nitrogen contents but provision of the substrate beyond $300 \mathrm{mg}$ resulted steady cessation in $\mathrm{H}_{2}$ production.

When the substrate loading was increased in this study, increase of inoculum age initially resulted in a significant increase in hydrogen production. At inoculum age of $48 \mathrm{~h}$ and substrate loading of $2 \mathrm{~g}$, hydrogen yield reached upto $598 \mathrm{ml} / \mathrm{L}$ of culture at fixed nitrogen content. Further increase in substrate loading resulted in decrease of $\mathrm{H}_{2}$ production (Figure 1B). Regarding the effect of substrate and nitrogen content on the volume of $\mathrm{H}_{2}$ production, it reached upto $607 \mathrm{ml} / \mathrm{L}$ when inoculum age was at its central point (Figure 1C). Further increase in substrate concentration and nitrogen content led to gradual decrease in the $\mathrm{H}_{2}$ volume. It could be concluded that critical substrate concentration was one of the major factors affecting the conversion rate of enzymatic hydrolysis of cellulose. Qi et al. [12] also reported slow reduction in hydrolysis yield with an increase in substrate concentration.
Such reduction of hydrolysis yield has been explained by enzymatic inactivation and decrease in reactivity of cellulosic substrate with proceeding of hydrolysis process [41]. In the present study, hydrogen yield appeared at the expense of monosaccharides. Glucose and xylose were mainly recruited by the bacterium Rhodobacter capsulatus- PK for hydrogen production. Table 3 explains the monosaccharides' concentration in exhausted/fermented broth while $\mathrm{H}_{2}$ production was still detectable probably at the expense of acetic acid produced during $\mathrm{H}_{2} \mathrm{SO}_{4}$ pretreatment process. Acetic acid is well recognized substrate for photofermentation by purple non sulfur bacteria [42]. While in case of enzymatic hydrolysis of WS $\mathrm{H}_{2}$ production process remained noticeable at slower rate probably at the expense of remaining sugars in fermentation broth (Table 3), because accumulation of acetate was not noticed here.

Xylose and glucose are reported substrates for $\mathrm{H}_{2}$ by different microorganisms such as $C$. acetobutylicum, C. butyricum and Rhodobacter capsulatus, [43-45]. Lignocellulosic biofuel production is not yet economically competitive with fossil fuels; therefore, successful utilization of all sugars is important for improving the overall economy [46]. It is expected that search of more microbial diversity capable of utilizing maximally the hydrolyzates, ingredients capable/construction of required characteristics possessing GMOs will add to the economics of biohydrogen production from lignocellulogic biomass.

\section{Confirmation experiments}

Prediction of $\mathrm{H}_{2}$ production at any tested parameter within the range of experimental design is achieved by employing second-order polynomial regression equation obtained from experimental data.

For better understanding and confirmation of $\mathrm{H}_{2}$ production from WS and validity of statistical experimental strategies different confirmation runs were performed (Table 8). Point prediction capability of the software with predicted $\mathrm{H}_{2}$ production rate lead to the idea of confirmation of the conditions located within the levels defined previously. The residual and percentage errors were calculated by comparing the actual and predicted $\mathrm{H}_{2}$ production rate. It can be seen from values listed in Table 8 that percentage errors between predicted and actual $\mathrm{H}_{2}$ production vary from $0.21 \%$ to $1.01 \%$. Therefore it can be assumed that developed statistical model is reasonably accurate. Thus central composite design of response surface can be accurately used for prediction and optimization of photofermentative $\mathrm{H}_{2}$ production from WS under the experimental conditions employed in this study. The model adequacy can be judged from residual's least square which is important to ensure for providing maximum approximation on relationship between factors and response when normal probability is 

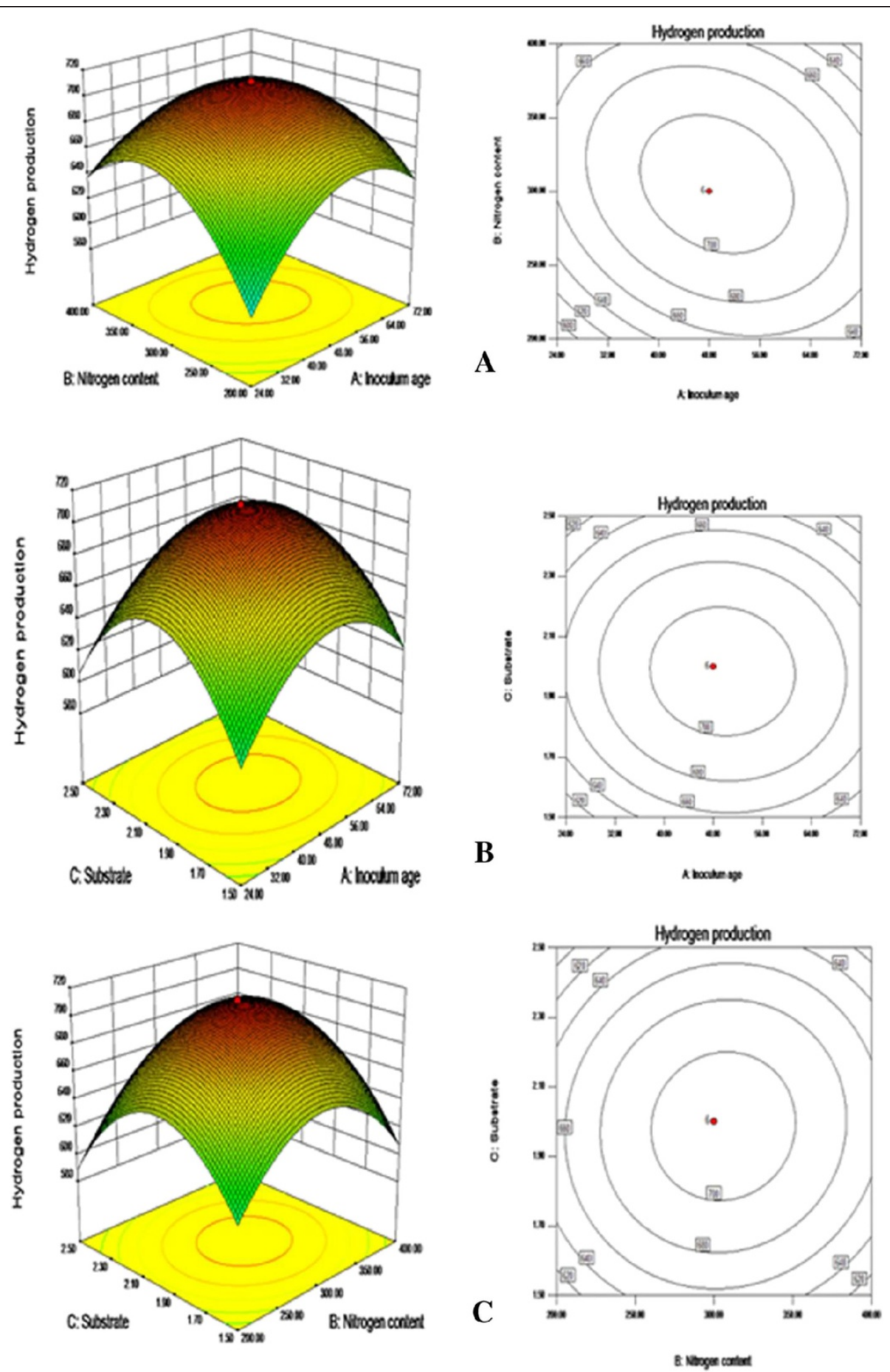

Figure 1 Response surface and contour plot of $\mathrm{H}_{2}$ production by Rhodobacter capsulatus-PK (SS-8) in WS-MIl showing combined effects of variables. i-e nitrogen content and inoculum age (A), substrate amount and inoculum age (B) and substrate amount and nitrogen content (C).

checked by normal probability plot of residuals. Straight line in Figure 2A approved the satisfaction of normality assumption. These results are indicative of maximum predictive response with constant variance and quadratic model accuracy Figure 2B.
Likewise, many attempts have been made by different investigators for identifying suitability of different lignocellulosic substrates as well as process conditions for enhanced hydrogen production. Optimization of some independent process variables (inoculum size, palm oil 
Table 8 Confirmation experiments of CCD (RSM) model for Rhodobacter capsulatus-PK (SS-8) and enzymatically hydrolyzed WS

\begin{tabular}{llllccc}
\hline $\mathbf{X}_{\mathbf{1}}$ & $\mathbf{X}_{\mathbf{2}}$ & $\mathbf{X}_{\mathbf{3}}$ & \multicolumn{2}{l}{$\mathbf{H}_{\mathbf{2}}$ production $(\mathbf{m l})$} & & \\
& $(\mathbf{m g})$ & $\mathbf{( g )}$ & actual & predicted & residual & error (\%) \\
\hline 48 & 300 & 2.00 & 708.34 & 710.25 & -1.91 & 0.27 \\
24 & 300 & 2.50 & 611.23 & 605.61 & 5.62 & 0.92 \\
48 & 400 & 2.00 & 673.12 & 666.31 & 6.81 & 1.01 \\
48 & 300 & 2.50 & 651.05 & 649.55 & 1.50 & 0.23 \\
50 & 320 & 2.20 & 697.47 & 698.94 & -1.47 & 0.21 \\
40 & 280 & 1.70 & 683.09 & 681.15 & 1.94 & 0.28 \\
\hline$X_{1}=$
\end{tabular}

$\mathrm{X}_{1}=$ inoculum age:

$\mathrm{X}_{2}=$ nitrogen content;

$\mathrm{X}_{3}=$ substrate loading

mill effluent concentration, light intensity, agitation and $\mathrm{pH}$ ) by response surface methodology (RSM) has been reported by Jamil et al. [47]. Some other parameter's optimizations like glucose and glutamate concentrations and light intensity have been described by Box-Behnken design of RSM [15]. In several studies lignocellulosic material has been treated chemically and/or biologically for yielding reducing sugars and then employed for photofermentation. Anam et al. [30] reported the photofermentative hydrogen production potential of Rhodobium marinum upto $41 \pm 16 \mathrm{ml}$ from some reducing sugars obtained from $\mathrm{H}_{2} \mathrm{SO}_{4}$ hydrolysis of sugarcane bagasse. Recently Keskin and Hallenbeck [3] reported potential of $10.5,8.0$ and 14.0 moles of $\mathrm{H}_{2} / \mathrm{mol}$ of substrate from beet molasses, black streep molasses and sucrose, respectively by Rhodobacter capsulatus JP91.

\section{Conclusion}

Biohydrogen production was the highest from wheat straw that was enzyme hydrolysed followed by ammonia pretreatment. Yeast extract as nitrogen source, inoculum age and substrate loading for enzyme hydrolysis appeared to affect hydrogen production potential of Rhodobacter capsulatus-PK. Acid hydrolysate of the hemicellulose fraction of WS was comparatively less suitable than enzymatically treated hydrolysate due to its comparatively low sugar contents and presence of inhibitors (acetic acid and furfural) for biohydrogen production. According to regression equation of RSM model, the interactions of three tested variables (inoculum age, nitrogen contents and substrate concentration) on $\mathrm{H}_{2}$ production from pretreated wheat straw yielded nearly theoretical $\mathrm{H}_{2}$ production level. With inoculum age $48 \mathrm{~h}$, nitrogen content of $300 \mathrm{mg} / \mathrm{L}$ and $2.0 \mathrm{~g} / 100 \mathrm{~mL}$ of substrate loading, the $\mathrm{H}_{2}$ volume obtained was $712 \mathrm{ml} / \mathrm{L}$. The model, predicted accurately for maximum photofermentative hydrogen from hydrolysed lignocellulosic biomass.

\section{Future prospects}

Demonstration of biohydrogen yield from local bioresources indicates the feasibility of development of a scalable system for regenerative energy provision employing crop residues. A number of avenues can be pursued to increase yields, including exploration of variety of abundantly available lignocellulosic biomass. Complete utilization of monosaccharides of hydrolysates as well as appropriate adjustment of $\mathrm{C} / \mathrm{N}$ ratio could affect the efficiency of photofermentative process. Reduction of inhibitors concentrations is also important for the yield improvement. Lignocellulosic biofuel production is not yet economically competitive with fossil fuels; therefore, successful utilization of all sugars is important for improving the overall economy [45]. Other, additional metabolic alterations may be desirable and can be sought from newly developed metabolic flux analysis model of photosynthetic/photoheterotrophic bacterial growth and photofermentation [48]. Finally, light conversion efficiencies might be improved by use of proper light intensities through reduction in the size of the photosynthetic antennae, [49]. It is hoped that like many previously established biotechnological processes, benefiting the humans, inputs from different scientific sectors to this newly growing science would enable existence of a bright future for biofuels with concomitant waste management and provision of renewable and hence cleaner energy sources.

\section{Materials and methods Microorganism}

Rhodobacter capsulatus-PK was obtained from stock culture collection of Microbial Biotechnology lab., of University of the Punjab, Lahore, Pakistan. The bacterium was isolated from rice paddy field on Biebl and Pfennig medium [50] and has been reported for higher yield of $\mathrm{H}_{2}$ following photofermentation in a medium comprised mainly of $2 \%$ sugarcane bagasse [51]. The substrate replaced sodium succinate in the original medium described by Biebl and Pfennig [50]. Culture of the bacterium was revived in said medium. The growth was obtained by incubating the inoculated culture bottles at $30 \pm 2.0^{\circ} \mathrm{C}$ for $48 \mathrm{~h}$ under illumination of light intensity of $120-150 \mathrm{~W} / \mathrm{m}^{2}$ and then used as inocula in the subsequent experiments.

Figure 3 explores the whole process from preparing hydrolysate of WS employing dilute sulfuric acid pretreatment and enzymatic hydrolysis to photofermentative production of hydrogen. Wheat straw was washed, air dried and milled before passing through $1 \mathrm{~mm}$ sieve which was obtained from Moscow, Idaho, USA. The processed wheat straw was stored in plastic bags for further use at room temperature. Liquid 

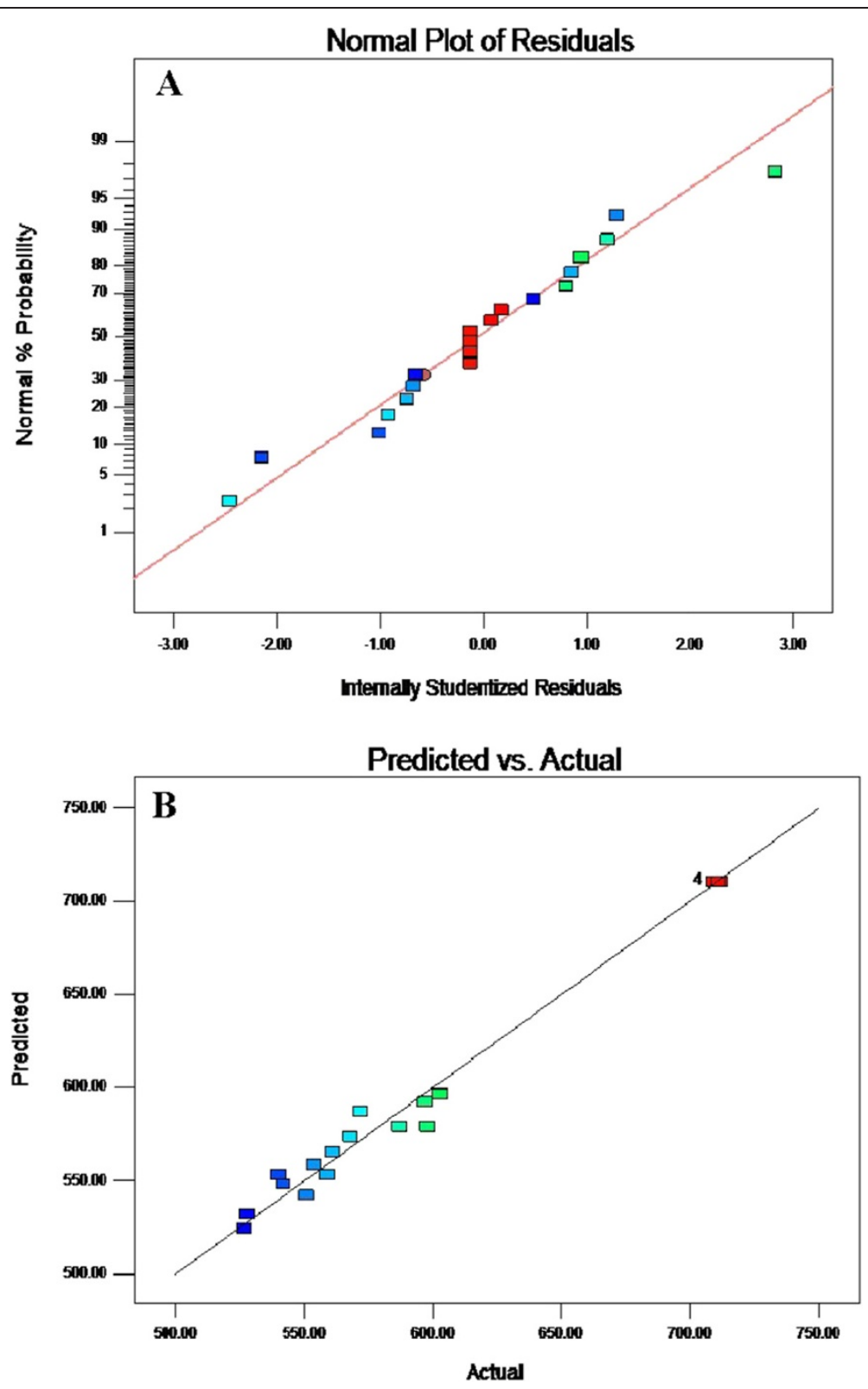

Figure 2 Response surface for $\mathrm{H}_{2}$ production by Rhodobacter capsulatus-PK (SS-8) in WS-MII. Normal probability of internally studentized residuals (A) and observed vs the predicted values (B) of CCD.

fraction obtained after dilute acid pretreatment of WS was separated via vacuum filtration and divided into two portions. One part was retained as non-detoxified liquid hydrolysate (NDLH) and other was rendered detoxified liquid hydrolysate (DLH) as described in the forthcoming paragraph. Both of the fractions were used as substrates for photofermentative production of hydrogen. While the setup containing Biebl and Pfennig [50] growth medium was used as control run (control-MII).
Pretreatment of wheat straw with dilute sulfuric acid

Protocol of dilute sulfuric acid pretreatment of wheat straw described by Chen et al. [52] was followed in these experiments. Numeral $(\mathrm{v} / \mathrm{v})$ concentrations of sulfuric acid from 1 to $7 \%$ were prepared and the wheat straw was suspended and stirred at room temperature in a given dilution at solid loading rate of $10 \%(\mathrm{w} / \mathrm{v})$. The mixtures were autoclaved at $121^{\circ} \mathrm{C}$ for $60 \mathrm{~min}$. The autoclaved and cooled liquid hydrolysates were then separated by centrifugation and after vacuum filtration 


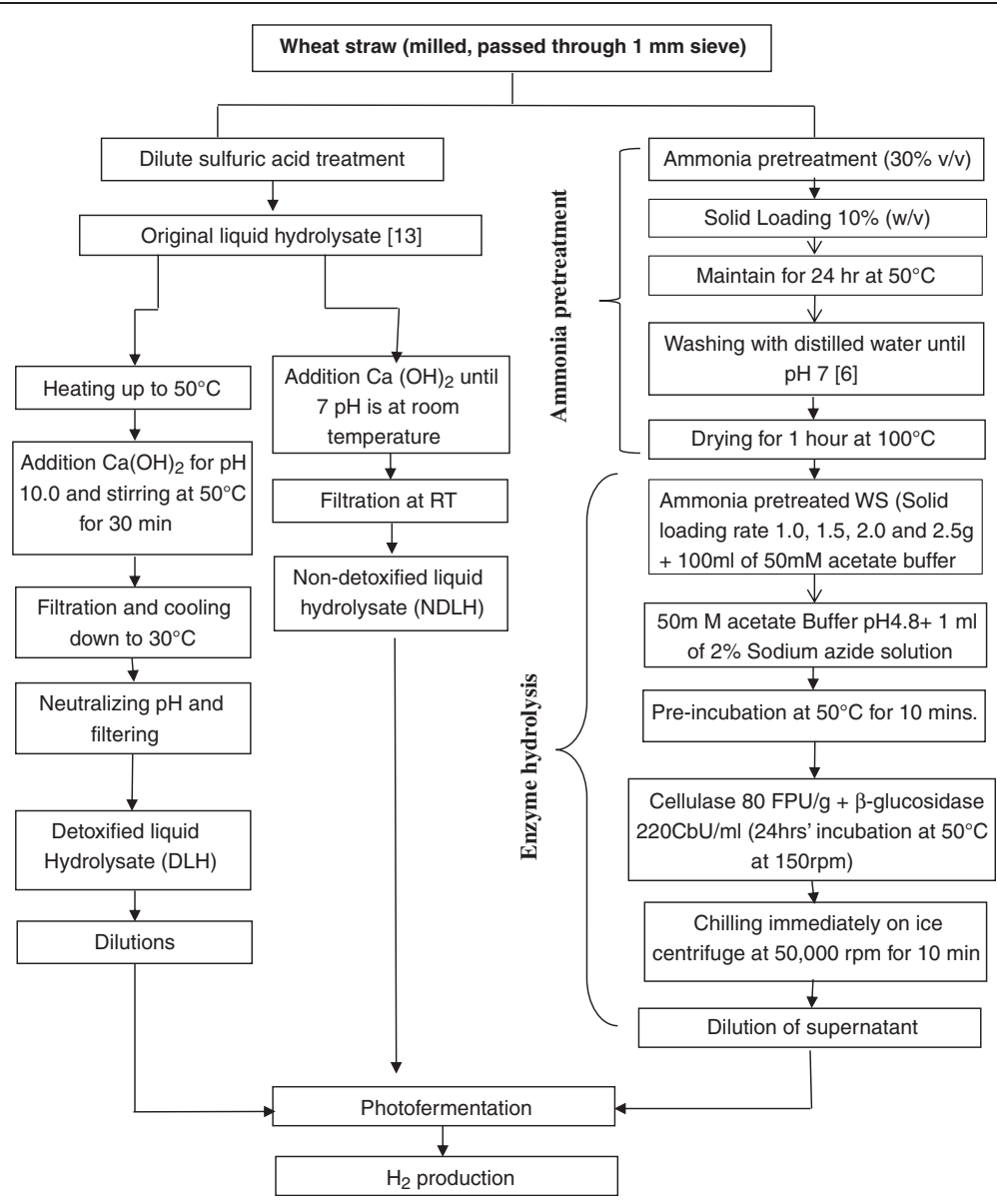

Figure 3 Flow chart indicating two routes for production of hydrogen from lignocellulosic biomass.

stored at $4^{\circ} \mathrm{C}$. The hydrolysate was detoxified by heating upto $50^{\circ} \mathrm{C}$ with continuous stirring with the help of a stir bar by addition of calcium hydroxide and $\mathrm{pH}$ was increased upto 10.0 in the process of overliming. This overlimed mixture was further stirred for $30 \mathrm{~min}$ with the help of stirring hot plate. The mixture was then filtered through $0.22 \mu \mathrm{m}$ membrane (Millipore, MA). The filtrate was allowed to cool upto $30^{\circ} \mathrm{C}$ and then sulfuric acid was added to attain $\mathrm{pH} 7$. The re-acidified hydrolysate was again filtered through $0.22 \mu \mathrm{m}$ Millipore filter for removal of precipitate formed. This detoxified liquid hydrolysate was then employed as a fermentation substrate for hydrogen production.

For NDLH calcium hydroxide was added to the acid treated liquid hydrolysate at room temperature to attain $7 \mathrm{pH}$. Followed filtration through $0.22 \mu \mathrm{m}$ Millipore filter the liquid served as respective fermentation substrate.

\section{Enzyme hydrolysis}

For this experiment WS was treated with $30 \%(\mathrm{v} / \mathrm{v})$ ammonia for 24 hour at $50^{\circ} \mathrm{C}$ with solid loading of $10 \%$ $(w / v)$ followed by washing with deionized water until
$\mathrm{pH}$ became 7. The substrate was then dried in oven at $100^{\circ} \mathrm{C}$ for one hour for ammonia removal. Thus pretreated WS was subjected to enzyme hydrolysis at solid loading rate of 1.0, 1.5, 2.0 and $2.5 \mathrm{~g} / 100 \mathrm{ml}$ in $50 \mathrm{mM}$ acetate buffer (pH 4.8). In each of the mixture $1 \mathrm{ml}$ of $2 \%$ sodium azide solution was added to avoid microbial contamination and then incubated for $10 \mathrm{mins}$ at $50^{\circ} \mathrm{C}$ and $150 \mathrm{rpm}$. Enzymatic hydrolysis was carried out with novozymes cellulase and $\beta$ glucosidase of $80 \mathrm{FPU} / \mathrm{g}$ and $220 \mathrm{CbU} / \mathrm{ml}$ activities, respectively by incubating the reactants at $50^{\circ} \mathrm{C}$, $150 \mathrm{rpm}$ for $24 \mathrm{hrs}$. At termination of the enzymatic hydrolysis a given mixture was chilled immediately on ice and centrifuged at $5000 \mathrm{rpm}$ for $10 \mathrm{~min}$. Then mixture of $20 \%$ and $40 \%$ of the enzymes and each of acid treated (detoxified and non-detoxified) hydrolysate, respectively was used in original growth medium (Biebl and Pfennig medium) as fermentation substrate. However, in the present study yeast extract upto $300 \mathrm{mg} / \mathrm{L}$ was employed as nitrogen source in order to make the medium nitrogen limited. In this study dilutions were made in order to lighten the color of both categories of the hydrolysats for effective absorbance of light in fermentation culture 
vessels as also reported by Zhu et al. [53], Eroglu et al. [54], Ozgur et al. [55], Boran et al. [56]. Seed inoculum $(10 \%, v / v)$ was then added to the culture medium. Overview of the process is shown in flow sheet (Figure 3). All experiments were performed under light intensity of 120 $150 \mathrm{~W} / \mathrm{m}^{2}$ at $30 \pm 2.0^{\circ} \mathrm{C}$ with initial $\mathrm{pH}$ 7. While mixture composition and initial concentration of fermentation sugars were given in Table 3.

Hydrogen yield was obtained by dividing the maximum hydrogen production $(\mathrm{ml} / \mathrm{L})$ by the quantity of substrate (sugars $\mathrm{g} / \mathrm{L}$ ) in the medium [57]. However, for cumulative hydrogen volume, it is described here that at each observational period all the amount of gases produced including $\mathrm{H}_{2}$ within the headspace of the batch culture fermenter was removed for analysis.

Response surface methodology (RSM) was used to explore an approximate functional relationship among three-level factorial design variables (Tables 4 \& 5) and response by using Design Expert software (Central Composite Design Expert Version 8.0.3, Statease, Minneapolis, USA) [58]; Eq. 1.

\section{Analytical methods}

$\mathrm{H}_{2}$ production was measured by using Gas chromatograph (GC, CP-3800, Varian, and Walnut Creek, CA) equipped with thermal conductivity detector. Nitrogen was employed as carrier gas and column used was HayeSep Q 80/100 Mesh Silcosteel.

Elemental contents of WS were analyzed with the help of elemental analyzer from Analytical Science Laboratory, Holm Research Center, College of Agriculture and Life Sciences, University of Idaho, Idaho, USA by means of combustion method (Combustion, ASA 29-2.2). One gram of WS was extracted by using the ASTM method [59]. Extractable contents were determined gravimetrically, while glucan, xylan, acid soluble and insoluble lignin were measured according to NREL procedure LAP-002 [60].

Different sugar contents like arabinose, galactose, glucose and xylose in treated and untreated WS were analyzed with the help of ion exchange chromatography system (Dionex ICS-3000) equipped with a CarboPac TM PA $20(4 \times 50 \mathrm{~mm})$ analytical column and CarboPac TM PA $20(3 \times 30 \mathrm{~mm})$ guard column (Dionex Corporation, CA). Membrane filtered $(0.22 \mu \mathrm{m})$ samples were subsequently eluted isocratically with $0.01 \mathrm{M} \mathrm{NaOH}$ after injection at a flow rate of $0.5 \mathrm{ml} / \mathrm{min}$. In a pulsed amperiometric detector analytes were detected and quantified against standard curves by electrochemical detection.

Different inhibitors produced in the hydrolysate were analyzed with high performance liquid chromatography, equipped with Biorad Aminex HPX-87H column (Bio-Rad Laboratories, CA) and refractive index detector according to Sluiter et al. [61]. While mobile phase was $0.005 \mathrm{M}$ sulfuric acid at a flow rate of $0.6 \mathrm{~mL} / \mathrm{min}$. Acid treated hydrolysate with more sugar contents and less concentration of inhibitors was selected for hydrogen production experiment.

\section{Competing interests}

The authors declare that they have no competing interests.

\section{Authors' contributions}

SSM participated in the conception, design, all experimental work, data collection and analysis, and drafted the manuscript. JIQ participated in the critical discussion and manuscript revision. QZ helped in mathematical modeling and SC participated in the critical discussion of the results. All authors read and approved the final manuscript.

\section{Acknowledgement}

First author is thankful Higher Education Commission of Pakistan for awarding IRSIP visit fellowship that was helpful in accomplishment of this work.

Received: 14 April 2013 Accepted: 27 September 2013

Published: 7 October 2013

\section{References}

1. Wen Hay JX, Wu TY, Teh CY, Jahim JM: Optimized growth of Rhodobacter sphaeroides O. U. 001 using response surface methodology (RSM). J Sci Ind Res 2012, 71:149-154.

2. Basak N, Das D: The prospect of purple non sulfur (PNS) photosynthetic bacteria for hydrogen production: the present state of the art. World J Microbial Biotechnol 2007, 23:31-42.

3. Keskin T, Hallenbeck PC: Hydrogen production from sugar industry wastes using single-stage photofermentation. Bioresour Technol 2012, 112:131-136.

4. Han H, Liu B, Yang H, Shen J: Effect of carbon sources on the photobiological production of hydrogen using Rhodobacter sphaeroides RV. Int J Hydrogen Energy 2012, 37:12167-12174.

5. Koku H, Erolu I, Gunduz U, Yucel M, Turker L: Aspect of the metabolism of hydrogen production by Rhodobacter sphaeroides. Int J Hydrogen Energy 2002, 27:1315-1329.

6. Han M, Moon SK, Kim Y, Kim Y, Chung B, Choi GW: Bioethanol production from ammonia percolated wheat straw. Biotechnology and Bioprocess Eng 2009, 14:606-611.

7. Wyman CE, Dale BE, Elander RT, Holtzapple M, Ladisch MR, Lee YY: Coordinated development of leading biomass pretreatment technologies. Bioresour Technol 2005, 96:1959-1966.

8. Taherzadeh MJ, Karimi K: Pretreatment of lignocellulosic wastes to improve ethanol and biogas production: a review. Int J Mol Sci 2008, 9:1621-1651.

9. Wyman CE: Biomass ethanol: Technical progress, opportunities, and commercial chanllenges. Ann Rev Energy Environ 1999, 24:189-226.

10. Wen Z, Liao W, Chen S: Hydrolysis of animal manure lignocellulosics for reducing sugar production. Bioresour Technol 2004, 91:31.

11. Chang V, Holtzapple M: Fundamental factors affecting biomass enzymatic reactivity. Appl Biochem Biotechnol 2000, 84-86:5-37.

12. Qi B, Chen X, Shen F, Su Y, Wan Y: Optimization of enzymatic hydrolysis of wheat straw pretreated by alkaline peroxide using response surface methodology. Ind Eng Chem Res 2009, 48:7346-7353.

13. Yu X, Zheng Y, Dorgan KM, Chen S: Oil production by oleaginous yeasts using the hydrolysate from pretreatment of wheat straw with dilute sulfuric acid. Bioresour Technol 2011, 102:6134-6140.

14. Chang YN, Huang J-C, Lee C-C: Use of response surface methodology to optimize culture medium for production of lovastatin by Monascus rubber. Enzyme Microb Technol 2002, 30:889-894.

15. Gosh D, Sobro IF, Hallenbeck PC: Optimization of hydrogen yield from single stage photofermentation of glucose by Rhodobacter capsulatus JP91 using response surface methodology. Bioresour Technol 2012, 123:199-206.

16. Gabrielyan L, Torgomyan H, Trchounian A: Growth characteristics and hydrogen production by Rhodobacter sphaeroides using various amino acids as nitrogen sources and their combinations with carbon sources. Int J Hydrogen Energy 2010, 35:12201-12207.

17. Remond C, Aubry N, Cronier D, Noel S, Martel F, Roge B, Rakotoarivonina H, Debeire $\mathrm{P}$, Chabbert B: Combination of ammonia and xylanase 
pretreatment: Impact on enzymatic xylan and cellulose recovery from wheat straw. Bioresour Technol 2010, 101:6712-6717.

18. Garcia-Cubero MT, Gonzalez-Benito G, Indacoechea I, Coca M, Bolado S: Effect of ozonolysis pretreatment on enzymatic digestibility of wheat and rye straw. Bioresour Technol 2009, 100:1608-1613.

19. Pan C-M, Fan Y-T, Zhao P, Hou H-W: Fermentative hydrogen production by the newly isolated Clostridium beijerinckii Fanp3. Int J Hydrogen Energy 2008, 33:5383-5391.

20. Liao W, Wen ZY, Hurley S, Liu Y, Liu CB, Chen SL: Effects of hemicelluloses and lignin on enzymatic hydrolysis of cellulose from dairy manure. Appl Biochem Biotechnol 2005, 124:1017-1030.

21. Yang B, Wyman CE: BSA treatment to enhance enzymatic hydrolysis of cellulose in lignin containing substrates. Biotechnol Bioeng 2006, 94:611-617.

22. Mohagheghi A, Ruth $M$, Schell DJ: Conditioning hemicellulose hydrolysates for fermentation: effects of overliming $\mathrm{pH}$ on sugar and ethanol yields. Process Biochem 2006, 41:1806-1811.

23. Pattra S, Sangyoka S, Boonmee M, Reungsang A: Bio hydrogen production from the fermentation of sugarcane bagasse hydrolysate by Clostridium butyricum. Int J Hydrogen Energy 2008, 33:5256-5265.

24. Aguilar R, Ramirez JA, Garrote G, Vazquez M: Kinetic study of the acid hydrolysis of sugarcane bagasse. J Food Eng 2002, 55:309-318.

25. Liu Y, Yu P, Song X, Qu Y: Hydrogen production from cellulose by co-culture of Clostridium thermocellum JN4 and thermoanaerobacterium thermosaccharolyticum GD17. Int J Hydrogen Energy 2008, 33:2927-2933.

26. De Vrije T, Bakker RR, Budde MAW, Lai MH, Mars AE, Claassen PAM: Efficient hydrogen production from the lignocellulosic energy crop Miscanthus by the extreme thermophilic bacteria Caldicellulosiruptor saccharolyticus and Thermotoga neapolitana. Biotechnology Biofuels 2009, 2:12.

27. Kaparaju P, Serrano M, Thomsen AB, Kongjan P, Angelidaki I: Bioethanol, biohydrogen and biogas production from wheat straw in a biorefinery concept. Bioresour Technol 2009, 100:2562-2568.

28. Tan H, Yang R, Sun W, Wang S: Peroxide-Acetic acid pretreatment to remove bagasse lignin prior to enzymatic hydrolysis. Ind Eng Chem Res 2010, 49:1473-1479.

29. Yue Z, Teater C, Maclellan J, Liu Y, Liao W: Development of a new bioethanol feedstock- Anaerobically digested fiber from confined dairy operations using different digestion configurations. Biomass Bioenergy 2011, 35:1946-1953.

30. Anam K, Habibi MS, Harwati UT, Susilaningsih D: Photofermentative hydrogen production using Rhodobium marinum from bagasse and soy sauce wastewater. Int J Hydrogen Energy 2012, 37:15436-15442.

31. Zhao Y, Wang Y, Zhu JY, Ragauskas A, Deang Y: Enhanced enzymatic hydrolysis of spruce by alkaline pretreatment at low temperature. Biotech Bioeng 2008, 99:1320-1328.

32. Hendriks ATWM, Zeeman G: Pretreatments to enhance the digestibility of lignocellulosic biomass. Bioresour Technol 2009, 100:10-18.

33. Kumar P, Barret DM, Delwiche MJ, Stroeve P: Methods for pretreatment of lignocellulosic biomass for efficient hydrolysis and biofuel production. Ind Eng Chem Res 2009, 48:3713-3729.

34. Hakobyan L, Gabrielyan L, Trchounian A: Yeast extract as an effective nitrogen source stimulating cell growth and enhancing hydrogen photoproduction by Rhodobacter sphaeroides strains from mineral springs. Int J Hydrogen Energy 2012, 37:6519-6526.

35. Kern $\mathrm{M}$, Klipp $\mathrm{W}$, Klemme JH: Increased nitrogenase- dependent $\mathrm{H}_{2}$ photoproduction by hup mutants of Rhodospirillum rubrum. Appl Environ Microbiol 1994, 60:1768-1774.

36. Shi $X Y, Y u$ HQ: Optimization of glutamate concentration and $\mathrm{pH}$ for $\mathrm{H}_{2}$ production from volatile fatty acids by Rhodopseudomonas capsulata. Lett Appl Microbiol 2005, 40:401-406.

37. Salerno MB, Park W, Zuo Y, Logan BE: Inhibition of biohydrogen production by ammonia. Water Res 2006, 40:1167-1172

38. Abo-Hashesh $M$, Hallenbeck PC: Microaerobic dark fermentative hydrogen production by the photosynthetic bacterium, Rhodobacter capsulatus JP91. Int J Low-Carbon Technologies 2012, 7:97-103.

39. Bashir MJK, Isa MH, Kutty SRM, Awang ZB, Aziz HA, Mohajeri S, Farooqi IH: Landfill leachate treatment by electrochemical oxidation. Waste Manage 2009, 29:2534-2541.

40. Basak N, Das D: Photofermentative hydrogen production using purple non sulfur bacteria Rhodobacter sphaeroides $0 . U .001$ in an annular photobioreactor: A case study. Biomass Bioenergy 2009, 33:911-919.
41. Gregg DJ, Saddler JN: Factors affecting cellulose hydrolysis and the potential of enzyme recycle to enhance the efficiency of an integrated wood to ethanol process. Biotech. Bioeng 1996, 51:375-383.

42. Barbosa MJ, Rocha JMS, Tramper J, Wijffels RH: Acetate as a carbon source for hydrogen production by photosynthetic bacteria. J Biotechnol 2001, 85:25-33.

43. Yokoi H, Maeda Y, Hirose J, Hayashi S: Hydrogen production by immobilized cell of Clostridium butyricum on porous glass beads. Biotechnol Tech 1997, 11:431-433.

44. Chin HL, Chen ZS, Chou CP: Fed batch operation using Clostridium acetobutylicum suspension culture as biocatalyst for enhancing hydrogen production. Biotechnol Prog 2003, 19:383-388.

45. Abo-Hashesh M, Ghosh D, Tourigny A, Taous A, Hallenbeck PC: Single stage photofermentative hydrogen production from glucose: an attractive alternative to two stage photofermentation or co-culture approaches. Int J Hydrogen Energy 2011, 36:13889-13895.

46. Hallenbeck PC, Ghosh D, Skonieczny YV: Microbiological and engineering aspects of biohydrogen production. Ind J Microbiol 2009, 49:48-59.

47. Jamil Z, Annuar MSM, Ibrahim S, Vikineswary S: Optimization of phototrophic hydrogen production by Rhodopseudomonas palustris PBUM001 via statistical experimental design. Int J Hydrogen Energy 2009, $7502: 7512$

48. Golomysova A, Gomelsky M, Ivanov PS: Flux balance analysis of photoheterotrophic growth of purple non sulfur bacteria relevant to biohydrogen production. Int J Hydrogen Energy 2010, 35:12751-12760.

49. Kondo T, Arakawa M, Hirai T, Wakayama T, Hara M, Miyaye J: Enhancement of hydrogen production by a photosynthetic bacterium mutant with reduced pigment. J Biosci Bioeng 2002, 93:145-150.

50. Biebl H, Pfennig N: Isolation of members of family Rhodosprillaceae. In The prokaryotes. volume 1. Edited by Starr MP, Stolp H, Truper HG, Balows A, Schlegel HG. New York: Springer; 1981:267-273.

51. Mirza SMA: Wastewater treatment and hydrogen production potential of locally isolated non sulfur purple bacteria. Lahore: PhD Thesis, University of the Punjab, Department of Zoology; 2012.

52. Chen CY, Liu CH, Lo YC, Chang JS: Perspectives on cultivation strategies and photobioreactor designs for photo-fermentative hydrogen production. Bioresour Technol 2011, 102:8484-8492.

53. Zhu H, Ueda S, Asada Y, Miyake J: Hydrogen production as a novel process of wastewater treatment-studies on tofu wastewater with entrapped $R$. sphaeroides and mutagenesis. Int. J. Hydrogen Energy 2002, 27:1349-1357.

54. Eroglu E, Gunduz U, Yucel M, Turker L, Eroglu I: Photobiological hydrogen production from olive mill wastewater as sole substrate sources. Int J Hydrogen Energy 2004, 29:163-171.

55. Özgür E, Afsar N, De Vrije T, Yücel M, Gündüz U, Claassen PAM, Eroglu I: Potential use of thermophilic dark fermentation effluents in photofermentative hydrogen production by Rhodobacter capsulatus. J Clean Prod 2010, 18:S23-S28.

56. Boran E, Ozgur E, Yucel M, Gunduz U, Eroglu I: Biohydrogen production by Rhodobacter capsulatus in solar tubular photobioreactor on thick juice dark fermenter effluent. J Clean Prod 2012, 31:150-157.

57. Fang HHP, Liu H, Zhang T: Phototrophic hydrogen production from acetate and butyrate in wastewater. Int J Hydrogen Energy 2005, 30:785-793.

58. Thakur C, Srivastava VC, Mall ID: Electrochemical treatment of a distillery wastewater: Parametric and residue disposal study. Chem Eng J 2009, 148:496-505.

59. ASTM: Standard Test Method for Ethanol-Toluene Solubility of Wood. In Annual Book of Wood Standards. Philadelphia, US: 1996.

60. Sluiter A, Hames B, Ruiz R, Scarlata C, Sluiter J, Templeton D, Crocker D: Determination of structural carbohydrates and lignin in Biomass. Golden, CO: Laboratory Analytical Procedure (LAP), National Renewable Energy Laboratory (NREL); 2008.

61. Sluiter A, Hames B, Ruiz R, Scarlata C, Sluiter J, Templeton D: Determination of Sugars, Byproducts, and Degradation Products in Liquid Fraction Process Samples. Golden, CO: Laboratory Analytical Procedure (LAP), National Renewable Energy Laboratory (NREL); 2006.

doi:10.1186/1754-6834-6-144

Cite this article as: Mirza et al:: Photo-biohydrogen production potential of Rhodobacter capsulatus-PK from wheat straw. Biotechnology for Biofuels 2013 6:144 